\title{
Information Transmission Among World Major Gold Futures Markets: Evidence From High Frequency Synchronous Trading Data
}

\author{
Rapeesorn Fuangkasem \\ Bangkok University, Bangkok, Thailand \\ Pornchai Chunhachinda, Sarayut Nathaphan \\ Thammasat University, Bangkok, Thailand
}

\begin{abstract}
This study examines the international information transmission among three major gold futures markets namely New York Mercantile Exchange in division of Commodity Exchange (COMEX), Multi Commodity Exchange (MCX), and Tokyo Commodity Exchange (TOCOM). The main concept of this research is no matter where gold futures traded, they share the same underlying asset. Two well-documented approaches, which are vector error correction model and information share, are utilized to measure the process of price discovery under this trivariate system. The uniqueness of this study is that it employs synchronous intraday time series which can mitigate the stale price problem from daily observations. The evidences indicate that the three gold futures prices are cointegrated and driven by the same fundamental factors. New arrival information disseminates efficiently among the three markets and the pricing information transmission among exchanges is very rapid. However, the lead-lag relationship among markets still exists with the dominance of COMEX gold futures as the centre of price discovery. The US gold futures market is the most efficient in processing information. Its role on price discovery and information can be attributed to COMEX's massive trading volume.
\end{abstract}

Keywords: information transmission, price discovery, vector error correction model, gold futures markets

Gold is a foundation asset within any long term savings or investment portfolio for centuries. From recent economic difficulties in Europe particularly in Greece, investors have to find a secure place to keep their wealth. Not surprisingly, gold is one of the answers in this situation. The possible reasons that underpin the widespread of interest in gold stem from many aspects: (1) portfolio diversification: Because correlation of return between gold and equity market is low, investing in gold can diversify risk and portfolios containing gold are generally

Corresponding author: Rapeesorn Fuangkasem, Ph.D., lecturer, School of Business Administration, Bangkok University, Thailand; research fields: international finance, capital market, derivatives, and information transmission. E-mail: rapeesorn@gmail.com.

Pornchai Chunhachinda, Ph.D., professor, Thammasat Business School, Thammasat University, Thailand; research fields: international finance, investments, foreign exchange market and risk management, international corporate finance, international investments, international financial markets and institution, asset pricing models and tests, and portfolio management. E-mail: pchunhachinda@hotmail.com.

Sarayut Nathaphan, Ph.D., assistant professor, Thammasat Business School, Thammasat University, Thailand; research fields: portfolio management, asset pricing, and risk management. E-mail: sarayut.mark@gmail.com. 
less volatile than those that do not; (2) inflation and currency hedge: Because over the long term, gold retains its purchasing power. Also, gold is employed as a hedge against fluctuations in currencies, particularly the United States Dollar (USD). A fall in the USD relative to the other main currencies produces a rise in the gold price; and (3) risk management: Because gold is significantly less volatile than most commodities and even much less volatile than many equity indices. Then, gold helps to manage risk more effectively by protecting against infrequent or unlikely but consequential negative events.

Demand of gold for investment purpose is expected to increase dramatically because there is a number of newly coming gold futures markets, exchange traded funds (ETFs), and other innovative products. Nowadays, gold attracts many investors' attention and urges them to allocate more weight to gold in their portfolio. Gold has been shifting from inflation protector commodity to a high-return investing asset as it yields $25.04 \%$, $29.24 \%$, and $8.93 \%$ annual return in 2009, 2010, and 2011, respectively. Gold price keeps rallying and reaches its peak, approximately 1,900 USD/oz in August 2011. Gold prices are also determined by demand and supply dynamic. On demand side as shown in Table 1, gold consumption comes from three major sectors: jewelry, technology, and investment. On the other side, there are three major gold suppliers: gold mine production, central bank activity, and gold recycling.

Table 1

World Gold Demand and Supply During 2009 and 2011

\begin{tabular}{|c|c|c|c|c|c|c|c|}
\hline \multirow[t]{2}{*}{ Year } & \multicolumn{2}{|c|}{2009} & \multicolumn{2}{|c|}{2010} & \multicolumn{2}{|c|}{2011} & \multirow{2}{*}{$\begin{array}{l}2011 \text { vs } 2010 \\
\% \text { change }\end{array}$} \\
\hline & Tonnes & $\%$ & Tonnes & $\%$ & Tonnes & $\%$ & \\
\hline \multicolumn{8}{|l|}{ Demand } \\
\hline Jewelry & 1,814 & $50 \%$ & 2,017 & $50 \%$ & 1,963 & $48 \%$ & $-2.68 \%$ \\
\hline Technology & 410 & $11 \%$ & 466 & $12 \%$ & 464 & $12 \%$ & $-0.43 \%$ \\
\hline Investment & 1,396 & $39 \%$ & 1,568 & $39 \%$ & 1,641 & $40 \%$ & $4.66 \%$ \\
\hline Total demand & 3,620 & $100 \%$ & 4,051 & $100 \%$ & 4,068 & $100 \%$ & $0.42 \%$ \\
\hline \multicolumn{8}{|l|}{ Supply } \\
\hline Total mine supply & 2,371 & $58 \%$ & 2,600 & $62 \%$ & 2,822 & $71 \%$ & $8.54 \%$ \\
\hline Central bank activity & 34 & $1 \%$ & -77 & $-2 \%$ & -440 & $-11 \%$ & - \\
\hline Recycled gold & 1,695 & $41 \%$ & 1,641 & $39 \%$ & 1,612 & $40 \%$ & $-1.77 \%$ \\
\hline Total supply & 4,100 & $100 \%$ & 4,164 & $100 \%$ & 3,994 & $100 \%$ & $-4.08 \%$ \\
\hline
\end{tabular}

Note. Source: Thomson Reuters Gold Field Mineral Services (GFMS).

Gold differs from other agricultural commodities. The major uniqueness of this precious metal is standardize, durability, and storability. No matter where gold are traded, they have the same fundamentals. Although there are differences in purity, contract specification, or trading currency, gold price tends to exhibit the same pattern. According to Harris, McInish, Shoesmith, and Wood (1995), markets in which traded assets are fundamentally related to each other is termed as informationally linked markets. To the same concept, gold or any derivatives of gold that are traded on different exchanges can be applied to this concept. Moreover, informationally linked market concept is binding to cointegration mechanism stating that any assets that share the same fundamental should have a long run relationship. Then, it is expected that no matter what gold is traded in any markets, prices will be linked to one another and they should be equal. Otherwise, there will be arbitrage opportunities by simultaneously buying relatively low price and selling relatively high price. Undoubtedly, arbitrageurs and speculators would pay close attention to pricing relationship of these 
commodities across markets around the world. Gold's standard quality and storage characteristics enable arbitrage in cross-market trading. It seems apparent that the gold price reflects global forces rather than local factors. Therefore, this paper shows how information is transmitted across markets in international setting and which market does the price discovery take place.

Price discovery is one of the key functions of market microstructure. Schreiber and Schwartz (1986) defined price discovery as the search for an equilibrium price. Baillie, Booth, Tse, and Zabotina (2002) defined price discovery as gathering and interpreting news. Lehmann (2002) described it as the process by which efficient and timely incorporation of new information implicit in investors' trades is priced into market prices. The implicit efficient price is assumed to be driven only by new information because it already fully reflects all information available at the current time. All of these interpretations suggest that price discovery is a dynamic process in search of equilibrium state which is characterized by the fast adjustment of market prices from old equilibrium to the new equilibrium with the arrival of new information. As a result, the concepts of price discovery and market efficiency are tied together. The efficient market hypothesis requires no arbitrage opportunities and market prices that quickly reflect any new information affecting fundamental values. Also, market efficiency describes the arrival speed of market consensus or equilibrium price, there are many possible explanations why observed asset prices generally depart from their underlying efficient values. One of rational explanations is the existence of market frictions and the limitation of investors to process information set with precision. District transaction costs, regulations, liquidities, and other institutional factors make different contribution to price discovery. Understanding the dynamic nature of the price discovery process is important, because it reflects information transmission across markets, thereby providing an indication of price efficiency. Theoretically, when two informationally linked markets are faced with the new information arriving simultaneously, these markets should react simultaneously and uniformly. When both markets do not react contemporaneously, one market reacts faster and leads the other. The leading market that provides price discovery and the securities in the other markets is mispriced, at least temporarily. Security prices will eventually converge to equilibrium price set by the leading market.

The purpose of this paper is to investigate price discovery and information transmission among three major gold futures exchanges namely New York Mercantile Exchange in division of Commodity Exchange (COMEX) (US), Multi Commodity Exchange (MCX) (India), and Tokyo Commodity Exchange (TOCOM) (Japan). Since India has been stepping into global gold futures market and has become one of the world highest trading volumes, literature investigates these relationships after the coming of new gold futures player has rarely been studied. The organization of this paper is as follows: Section two represents selected literature reviews, section three illustrates how intraday synchronous trading data is constructed, section four describes the approaches for price transmission and price discovery measures, section five analyzes the empirical results, and section six concludes this paper.

\section{Literature Reviews}

In the equity market area, US markets are thought to play a leading role in price transmission among informationally linked exchanges. Many literatures provide evidences that US financial markets including derivatives markets transmit information to other markets than the other way around (Eun \& Shim, 1989; Kwan, Sim, \& Cotsomitis, 1995; Ghosh, Saidi, \& Johnson, 1999; Fung, Leung, \& Xu, 2001). Price discovery and 
information transmission in informationally linked markets have been extensively examined in the literatures. There are two major groups of price discovery literatures. The first approach, the temporal precedence or bivariate relationship between futures return and spot returns is explored by using lead-lag return regression, Vector Autoregressive (VARs), or Vector Error Correction Models (VECMs). The second approach presumes that securities must share one or more common factors and the proportion of price discovery contribution can be determined.

Although, there are a number of literatures regarding price discovery process, the majority of research investigates these relationships between spot equity index market return and futures index market return. The majority of studies state that futures market is the leading market (Kawaller, P. Koch, \& T. Koch, 1987; Stoll \& Whaley, 1990; Fleming, Ostdiek, \& Whaley, 1996; Pizzi, Economopoulos, \& O'Neill, 1998). The possible explanation for the lead of futures market is that investors face lower transaction costs. Fleming et al. (1996) provide the evidence that support this statement. They find that the relative rates of price discovery in the cash and futures markets are due to the difference in trading costs. Their empirical results support the trading-cost hypothesis that markets with lower trading costs will react more quickly to new information and tend to lead those with higher trading costs in price discovery. De Jong and Donders (1998) found that stock index futures leads the cash index partially due to lower trading costs in the futures market. Wang and Yau (2000) showed that a transaction cost, which is similar to a greater bid-ask spread, would reduce trading volume. Another possible explanation is that futures market enables investors to have higher degree of leverage.

The other approach presumes that securities must share one or more common factors and the proportion of price discovery contribution can be determined. Based on use of VECM, information share model are developed by Hasbrouck. Hasbrouck (1995) defines price discovery in terms of the variance of the innovations to the common factor. The information share model measures each market's relative contribution to this variance. This contribution is called the market's information share. More intuitively, the market with highest level of information share implies the leading role in the process of price adjustment.

Although there are a number of researches investigating information transmission between spot market and futures market in the domestic settings, papers investigating this relationship across countries are really limited. Summary of research development related to gold cases will be mentioned as follows.

Starting with Dhillon, Lasser, and Watanabe (1997), they initiate an hourly comparison of gold futures price volatility in international setting. The price data in this study is comprised of open, close, high, and low futures trading prices for nearby gold futures contracts of COMEX and TOCOM from July 1987 through May 1992. There are three subsamples in this study: (1) July 1987 to October 1989 represents a subsample in which Japanese market is characterized by Walrasian-type trading and relatively low volume; (2) November 1989 to March 1991 also represents Walrasian-type trading ${ }^{1}$ but a comparatively higher TOCOM volume; and (3) April 1991 through May 1992 represents the continuous TOCOM trading with the highest volume compared with others. The evidences indicate that TOCOM price in continuous trading markets exhibit greater intraday

\footnotetext{
1 The Walrasian auctioneering method of price determination consists of six discrete trading sessions (evenly separated from 9.00 to 15.30) in which an agreed upon price was decided for each commodity by competitive bidding. The auctioneer would then either raise or lower the price until there were an equal number of sell and buy orders, at which point a trade was recorded at that price, thereby ending the session.
} 
volatility than prices generated in Walrasian auction markets. In addition, more information appears to be released in gold markets during US trading hours relative to Japan.

$\mathrm{Xu}$ and Fung (2005) examine patterns of cross-market information flows for gold, platinum, and silver futures contracts traded on both US and Japanese markets. Xu and Fung extend study of Dhllion et al. (1997) in several ways. First, three precious metals futures contracts dual-listed in US and Japanese markets between 1994 and 2001 are investigated, instead of comparing the volatility within these two markets as in the case of Dhillion et al. (1997). In this study, Xu and Fung apply a bivariate ARMA-GARCH model to investigate the market linkages. The bivariate ARMA-GARCH model allows simultaneous analysis of the pricing transmission and volatility spillover. Second, both daily and intraday information flows are analyzed. Since US and Japanese are in different time zones, one market opens in the next of the closing of the other market. Trading information in US market can be investigated the effect toward the opening price when Japanese market opens following the closing of the US market. Inversely, it can be investigated how trading information in Japan after the market closes affects the opening price of the US market. Finally, US and Japan are mutually regarded as financial center of global precious metal futures market. This study would shed lights on which country has more important information and on the direction of information transmission across the two markets for these three precious metal futures. Sample period starts from November 1994 to March 2001. The daily open and close prices of the metals futures in Japan are adjusted to US dollars using daily exchange rate. The results indicate that the pricing transmission across US and Japan is strong and significant. The US information appears to play a leading role in the futures market. Results of the volatility analysis indicate that both US and Japanese market receive important information from the other market, and there are strong feedback effects across the two markets. Significance of the feedback appears to be similar, implying that both markets have similar influence on the other market.

Bhar and Hamori (2004) investigate the pattern of information flow between the percentage price change and the trading volume in gold futures contracts. The daily New York Mercantile Exchange (NYMEX) settlement price data from January 3, 1990 to December 27, 2000 are the sample period. The AR-GARCH model is used because of its suitability to futures contracts. Schwarz Baynesian Information Criteria (SBIC) is used to choose the final model from various possible AR-GARCH specifications. The lag order of AR part or the conditional mean dynamic is chosen to be five for price data and 10 for trading volume data. For the conditional variance dynamics, it is specified as a GARCH $(a, b)$ model where $a$ is the number of ARCH terms and $b$ is the number of GARCH terms. The GARCH $(2,1)$ model is chosen for the percentage price change, while the GARCH $(1,1)$ model is chosen for trading volume. The results from this study show that the information flows between the price change and trading volume affect not only their mean movements but also volatility movements in these markets. The variance of the percentage price change has an effect on the percentage price change variance, which is indicative of the sequential information linkage. This evidence is different from those found earlier for other commodity futures.

Chaihetphon and Pavabutr (2009) examine the price discovery process of gold futures contracts in the MCX of India over the period of 2003-2007. Vector error correction model is employed to show that futures price of standard and mini gold futures contract lead spot price indicating that price discovery occurs in the futures market. Also, this study compares the contributions to price discovery of standard and mini gold futures contracts traded on electronic platform. Although mini contract captures only $2 \%$ of trading value on the MCX, it contributes to approximately $37 \%$ to price discovery. 
Furthermore, Liu and An (2011) investigate information transmission and information share for copper and soybean in Chinese spot, Chinese futures market, and US futures commodity markets. Daily data of copper and soybean for spot market is obtained from Shanghai Metal Market and a state-owned internet information company respectively. For futures market, data of Chinese copper and soybean is retrieved from Shanghai Futures Exchange (SHFE) and Dalian Commodity Exchange (DCE) and data of US copper and soybean is retrieved from NYMEX and Chicago Board of Trade (CBOT) respectively. The sample period is from January 2, 2004 to December 31, 2009. The trading hours of Chinese spot markets do not overlap at all with those of NYMEX or CBOT markets. In contrast, US copper and soybean futures are traded almost 24 hours a day, then their trading time covers the entire trading period of Chinese futures markets (SHFE and DCE). Thus, there is both overlapping and non-overlapping trading hours. To make data for Chinese and US futures price comparable, the daily closing price of NYMEX and CBOT futures contracts are converted into RMB per ton. To examine information transmission, the VECM-GARCH model and information share approach are used. The evidences show that the proportions of the information share attributed to the Chinese futures, Chinese spots and US futures are $39 \%, 18 \%$, and $43 \%$ respectively for copper while the corresponding numbers for soybeans are $40 \%$, $18 \%$, and $42 \%$ respectively. Therefore, US futures markets contribute most to the price discovery process.

To summarize, most studies on international linkages across futures markets of the same underlying asset suggest that there are stronger international market linkages in highly traded commodities as compared to relatively less traded commodities. Moreover, the developed markets (in terms of volume and number of derivatives products) play a dominant role in price discovery process.

\section{Data Construction}

In term of trading volume, the three major markets: COMEX, TOCOM, and MCX dominate the world gold futures trading (as shown in Table 2). Trading volume is standardized in a unit of million troy ounces. It is clear that COMEX still dominates world gold futures trading while TOCOM and MCX share the global gold futures trading volume around $8 \%-10 \%$.

Table 2

Trading Volume of Three Major Gold Futures Markets

\begin{tabular}{|c|c|c|c|c|c|c|}
\hline \multirow[b]{2}{*}{ Year } & \multicolumn{2}{|c|}{ COMEX } & \multicolumn{2}{|c|}{$\mathrm{MCX}^{* *}$} & \multicolumn{2}{|c|}{$\mathrm{TOCOM}^{* *}$} \\
\hline & $\begin{array}{l}\begin{array}{l}\text { Volume } \\
(\mathrm{m} \mathrm{t} \mathrm{oz})^{*}\end{array} \\
\end{array}$ & $\begin{array}{l}\begin{array}{l}\text { Percent } \\
(\%)\end{array} \\
\end{array}$ & $\begin{array}{l}\begin{array}{l}\text { Volume } \\
(\mathrm{m} \mathrm{t} \mathrm{oz})^{*}\end{array} \\
\end{array}$ & $\begin{array}{l}\text { Percent } \\
(\%)\end{array}$ & $\begin{array}{l}\text { Volume } \\
(\mathrm{m} \mathrm{t} \mathrm{oz})^{*}\end{array}$ & $\begin{array}{l}\text { Percent } \\
(\%)\end{array}$ \\
\hline 2009 & $3,517.62$ & 80.78 & 437.91 & 10.06 & 399.14 & 9.17 \\
\hline 2010 & $4,479.08$ & 84.26 & 436.70 & 8.21 & 400.15 & 7.53 \\
\hline 2011 & $4,931.98$ & 82.88 & 491.13 & 8.25 & 527.48 & 8.86 \\
\hline
\end{tabular}

Notes. "Aggregate trading volume in each exchange is in million troy ounces, " MCX and TOCOM trading volume is converted from kilogram to troy ounce (one troy ounce is equal to 31.1034768 grams). Source: COMEX, TOCOM, and MCX.

Since there are more than one gold futures contracts traded in each market, the most liquid gold futures contract is applied to create data set. Then, for all markets, the standard contracts are chosen. The details of each gold futures contract specification are shown in Table 3.

Moreover, when any futures contract reaches its maturity date, the following futures series will be used instead. The retrieved trading prices from Bloomberg Pro for each market are quoted in its domestic currency. Also, they are quoted in different unit of gold measurement. Gold futures contract is quoted in USD per troy 
ounce in US, Japanese Yen (JPY) per gram in Japan, and Indian Ruppee (INR) per 10 grams in India. To make price of gold futures comparable, prices of MCX and TOCOM are converted to price in USD per troy ounce format $^{2}$.

According to Fung, Leung, and Xu (2001), they show the evidence that the strong interactions in term of pricing are observed from US futures market and other futures exchanges. The key conclusion is that the cross-market pricing transmission values from the US to other market are comparatively larger than those from the other way around. Thus, Fung et al. (2001) show evidences that US market plays a leading role in term of pricing information transmission across market. However, the majority of the researches including Fung et al. (2001) use daily data to examine this relationship. Although there are some studies use close-to-open price (meaning that using close price of US market and open price of the other market) to reduce the trading time different between market, the non-synchronous problem still exists due to the stale price of the close or open trade used in previous studies. To mitigate this shortcoming and to obtain more precise measurement of information flow across markets, five-minute intraday analysis is applied in this research. Since the US gold futures market has been operating almost 24 hour a day but those of Japan and India are not. There are both overlapping and non-overlapping trading hour. To investigate the price transmission across markets in simultaneous trading time, only overlapped trading times among three exchanges is examined. Due to time zone difference, the time of Japanese market and Indian market located is converted to New York time. After matching, there are 10 hours per trading day of synchronized trading time of these three markets (see Figure 1).

Table 3

Details of the Gold Futures Contract Specifications

\begin{tabular}{llll}
\hline & COMEX & TOCOM & MCX \\
\hline Year of trading & 1974 & 1982 & 2003 \\
Underlying asset & Fine gold bar & Fine gold bar & Fine gold bar \\
Contract size (standard) & $100 \mathrm{t} \mathrm{oz}$ & 1 kilogram & 1 kilogram \\
Quality specification & 0.995 purity & 0.995 purity & 0.995 purity \\
Price quote & USD per t oz & JPY per gram & INR per 10 grams \\
Tick size & USD 0.10 per t oz & JPY 1 per gram & INR 1 per 10 grams \\
Settlement type & Physical delivery & Physical delivery & Physical delivery \\
\hline
\end{tabular}

Note. Source: COMEX, MCX, and TOCOM.

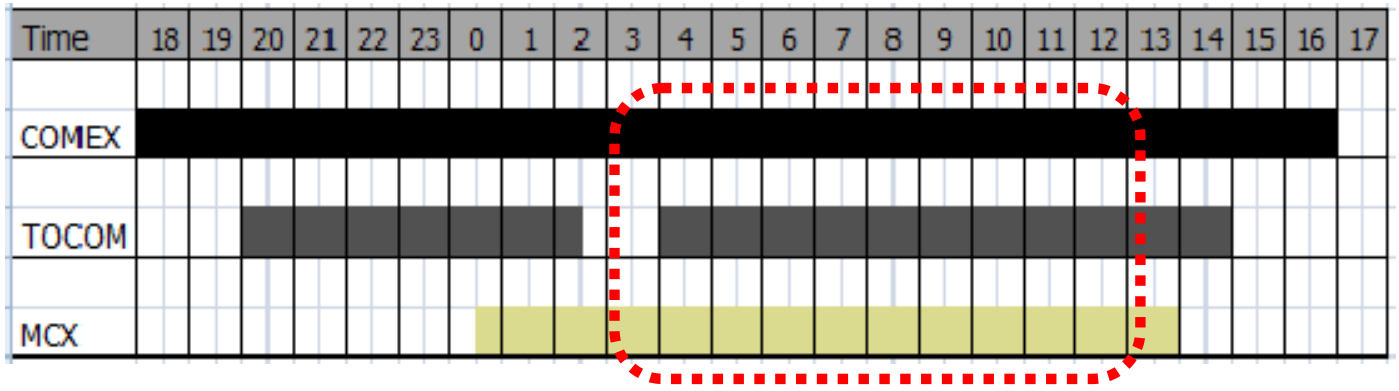

Figure 1. Gold futures trading hours of three major exchanges (New York time).

For gold futures trading hours, COMEX operates almost 24 hours a day but has a 45-minute break

\footnotetext{
${ }^{2}$ MCX (USD per $\mathrm{t}$ oz) $=1$ gram price of gold in Japan $\mathrm{x} 31.1034768 /(\mathrm{INR} / \mathrm{USD})$ TOCOM $($ USD per $\mathrm{t}$ oz) $=10$ gram price of gold in India x 31.1034768/(JPY/USD) / 10 (1 troy ounce $=31.1034768$ grams).
} 
starting from 5:15 P.M. to 6:00 P.M., MCX has operating hour from 10:00 A.M. to 11:30 P.M., Mumbai time (0:30 A.M. to 2:00 P.M., New York time), and TOCOM has two trading sessions per day. The day session starts from 9:00 A.M. to 3:30 P.M., Tokyo time (8:00 P.M. of previous day to 2:30 A.M., New York time) and the night session starts from 5:00 P.M. to 4:00 A.M. of the following day, Tokyo time (4:00 A.M. to 3:00 P.M., New York time). To construct overlapped time series dataset, five-minute interval data set from 4:00 A.M. to 1:00 P.M., New York time is applied. It is worth to mention that this data set is selected on the bias to COMEX and TOCOM. For COMEX and MCX, the selected trading time is partially in an out-of-normal local business time (approximately five of nine hours). This selection bias is more pronounced in Japan case because the synchronous trading hours are all in night session in Tokyo time. This might be the case because many financial institutions who might be the major players in price discovery contribution are close.

Because the purpose of this study is to investigate the price discovery and information transmission among markets, the observed data should be collected in the highly volatile period in order to precisely identify which market the price discovery take place. Thus, the observed period starting from April 2011 to August 2011 is selected. The intraday futures returns are constructed from the futures price data as $\log \left(\mathrm{P}_{t} / \mathrm{P}_{\mathrm{t}-1}\right)$, where $\mathrm{P}_{\mathrm{t}}$ is the futures price at time $t$. For calculating the five-minute intraday return, if there is no trading at the end of the five minutes, the closest trading price prior to the end of the five minute is used as the closing value of that five-minute interval. If any of the markets experience a holiday or missing data interval, the data for that day or interval will be omitted for all three markets. After making these adjustments, 8,066 observations remain.

After converting price of MCX and TOCOM, all gold futures prices are quoted in USD per troy ounce in the purity of 0.995 (reported in Table 4). On average, the highest gold futures prices are originated in Indian market at the value of USD 1,555 while price of gold futures in US and Japan are almost the same at the value of USD 1,532 to 1,534. The returns of gold futures contract in high frequency data are extremely low. The average returns of COMEX, MCX, and TOCOM are 0.0000018, 0.0000019, and 0.0000019, respectively. In daily interval, the average return is $0.0012,0.0010$, and 0.0007 for COMEX, MCX, and TOCOM, respectively.

Table 4

Summary Statistics of Five-Minute Intraday Data

\begin{tabular}{|c|c|c|c|c|c|c|c|c|c|}
\hline \multirow[b]{2}{*}{ Statistics } & \multicolumn{3}{|c|}{ COMEX } & \multicolumn{3}{|c|}{ MCX } & \multicolumn{3}{|c|}{ TOCOM } \\
\hline & $\begin{array}{l}\text { Price } \\
\text { (USD) }\end{array}$ & $\begin{array}{l}5 \text {-minute } \\
\text { return }(\%)\end{array}$ & $\begin{array}{l}\text { Daily } \\
\text { return (\%) }\end{array}$ & $\begin{array}{l}\text { Price } \\
\text { (USD) }\end{array}$ & $\begin{array}{l}5 \text {-minute } \\
\text { return }(\%)\end{array}$ & $\begin{array}{l}\text { Daily } \\
\text { return (\%) }\end{array}$ & $\begin{array}{l}\text { Price } \\
\text { (USD) }\end{array}$ & $\begin{array}{l}5 \text {-minute } \\
\text { return }(\%)\end{array}$ & $\begin{array}{l}\text { Daily return } \\
(\%)\end{array}$ \\
\hline Mean & 1,532 & $1.8 \mathrm{E}-05$ & 0.0012 & 1,555 & $1.9 \mathrm{E}-05$ & 0.0010 & 1,534 & $1.9 \mathrm{E}-05$ & 0.0007 \\
\hline Med & 1,523 & 0.0000 & 0.0016 & 1,543 & 0.0000 & 0.0007 & 1,525 & 0.0000 & 0.0008 \\
\hline Max & 1,682 & 0.0156 & 0.0334 & 1,705 & 0.0191 & 0.0248 & 1,688 & 0.0268 & 0.0432 \\
\hline Min & 1,416 & -0.0321 & -0.0315 & 1,431 & -0.0348 & -0.0276 & 1,419 & -0.0595 & -0.0562 \\
\hline Std & 56.01 & 0.0009 & 0.0085 & 52.50 & 0.0009 & 0.0070 & 57.17 & 0.0013 & 0.0092 \\
\hline Obs & 8,066 & 8,065 & 261 & 8,066 & 8,065 & 261 & 8,066 & 8,065 & 261 \\
\hline
\end{tabular}

Notes. Std-Standard deviation, Obs-Number of observations.

Moreover, it can be seen that prices of gold futures are not exactly the same in any exchange. This is basically because the difference in domestic risk-free rate for each country and this interest rate is generally 
used to calculate futures price. Not surprisingly, US and Japan that are facing economic recession have lowest domestic interest rate. Then, they would yield relatively lower gold futures price. In contrast, due to higher interest rate comparative to the remaining, MCX gold futures prices keep standing on the highest values.

\section{Methodology}

As the possibility to allow for the simultaneous analysis of return in the model, a multivariate vector error correction model is employed to investigate the lead-lag relationships among gold futures that are traded in the US, Japanese, and Indian futures markets. This section explains the VECM model used in this study for analyzing information transmission in term of price in informationally linked gold futures markets.

\section{Multivariate Vector Error Correction Model}

To examine patterns of price transmission across various markets, multivariate VECM approach to describe price interactions among various markets. If the futures prices traded in these three markets are cointegrated, short run relationship or price transmission can be explained through vector error correction model.

The vector error correction model is written as:

$$
\begin{aligned}
& r_{1, t}=\mu_{1}+\sum_{i=1}^{p} \alpha_{1, i} r_{1, t-i}+\sum_{j=1}^{q} \beta_{1, j} r_{2, t-j}+\sum_{m=1}^{s} \gamma_{1, m} r_{3, t-m}+\theta_{1}\left(P_{2, t-1}-P_{1, t-1}\right)+\tau_{1}\left(P_{3, t-1}-P_{1, t-1}\right)+\varepsilon_{1, t} \\
& r_{2, t}=\mu_{2}+\sum_{i=1}^{p} \alpha_{2, i} r_{1, t-i}+\sum_{j=1}^{q} \beta_{2, j} r_{2, t-j}+\sum_{m=1}^{s} \gamma_{2, m} r_{3, t-m}+\theta_{2}\left(P_{1, t-1}-P_{2, t-1}\right)+\tau_{2}\left(P_{3, t-1}-P_{2, t-1}\right)+\varepsilon_{2, t} \\
& r_{3, t}=\mu_{3}+\sum_{i=1}^{p} \alpha_{3, i} r_{1, t-i}+\sum_{j=1}^{q} \beta_{3, j} r_{2, t-j}+\sum_{m=1}^{s} \gamma_{3, m} r_{3, t-m}+\theta_{3}\left(P_{1, t-1}-P_{3, t-1}\right)+\tau_{3}\left(P_{2, t-1}-P_{3, t-1}\right)+\varepsilon_{3, t}
\end{aligned}
$$

Where:

$P_{1, t}, P_{2, t}$, and $P_{3, t}$ are the logarithmic prices of COMEX, MCX, and TOCOM gold futures contracts on date $\mathrm{t}$, respectively.

$r_{1, t}=P_{1, t}-P_{1, t-1}, r_{2, t}=P_{2, t}-P_{2, t-1}$, and $r_{3, t}=P_{3, t}-P_{3, t-1}$ correspond to respective returns of these futures. Moreover, it is also assumed that $\varepsilon_{t}=\left(\varepsilon_{1, t}, \varepsilon_{2, t}, \varepsilon_{3, t}\right)^{T} \mid \Omega_{t-1} \sim t\left(0, \Sigma_{t}\right)$.

$\Omega_{t-1}$ is the information set at $\mathrm{t}-1, \Sigma_{t}=\left\{\rho_{i, j} \sigma_{i, t} \sigma_{j, t}\right\}$ is the $4 \times 4$ time-varying conditional covariance matrix and $\rho_{i, j}$ is the conditional correlation coefficient between error terms $\varepsilon_{i}$ and $\varepsilon_{j}$.

This approach is widely used in the literatures, including Liu and An (2011), to describe price interactions among various informationally linked markets. This adjusted multivariate VECM can capture both the short-term and long-term effects of information flow across markets. To be more specific, short term effects $(\theta, \tau)$ are reflected by cross-market lagged returns in these equations, and long-term effects $(\alpha, \beta, \gamma)$ are captured by long-run equilibrium errors, defined as the difference in the last period's market prices between any two markets. If the estimation results of these long-term effect terms are significant, it implies that other 
markets can predict return in this market. To further explain the equation above, the error correction terms $(\theta, \tau)$ measure the speed of adjustment. At least, one of those terms $\left(\theta_{1}, \theta_{2}, \theta_{3}, \tau_{1}, \tau_{2}, \tau_{3}\right)$ is anticipated to be non-zero and statistically significant to prove that the prices of these gold futures are responsive to last period's equilibrium error. Any significant positive $\theta$ or $\tau$ implies that a change in this particular exchange results in price adjustment in other markets. Price discovery is supposed to occur in this market and it also implies that this exchange is a leading market. On the other hand, any significant negative $\theta$ or $\tau$ implies that this market reacts to the price change from other markets. However, in this multivariate case, if there are more than one significant positive error correction terms, the relative magnitude of any coefficients will judge which one is the leading market.

\section{Price Discovery Contribution}

In addition, this paper examines the proportion of price discovery of major gold futures markets by following Hasbrouck (1995) information share procedure. Hasbrouck's model extracts the price discovery process using the variance of innovations to the common factor. This approach uses cointegration to restrict multiple market prices to share a common efficient price and both approaches use a VECM for estimation purposes.

Hasbrouck information share model considers the contributions of innovations in each market to the total variance. Recall Engle and Granger's (1987) VECM:

$$
\Delta Y_{t}=\Pi Y_{t-1}+\sum_{i=1}^{k} A_{i} \Delta Y_{t-i}+\varepsilon_{t}
$$

where $Y_{t}=P_{1, t}, P_{2, t}, P_{3, t}$. Also, $\Pi=\alpha \beta^{T}$, and $\alpha$ and $\beta$ are $n \times(n-1)$ matrices. Each column of $\alpha$ is the error correction terms, and matrix $\beta$ consists of the $n-1$ cointegrating vectors. The residuals $\varepsilon_{t}$ are serially uncorrelated and have a covariance matrix denoted by $\Sigma$. Then, Equation 4 above can be transformed into an integrated form of a vector moving average (VMA) as follows:

$$
Y_{t}=Y_{0}+\Psi(1)\left(\sum_{i=1}^{t} \varepsilon_{i}\right)+\Psi^{*}(L) \varepsilon_{t}
$$

where (1) is a column vector of ones in a trivariate system, $\beta^{T} \Psi(1)=0, \Psi(1) \alpha=0$, and $\Psi^{*}$ is a matrix polynomial in the lag operator. The $\Psi(1)\left(\sum_{i=1}^{t} \varepsilon_{i}\right)$ term captures the random walk component that is permanently impounded into gold prices while the $\Psi^{*}(L) \varepsilon_{t}$ term is the transitory component with zero-mean and stationary covariance which does not have a permanent impact on $Y_{t}$. The implicit efficient price is denoted by the common stochastic trend in cointegrating system. Hasbrouck (1995) defines a market's contribution to price discovery as its proportion of the efficient price innovation variance, i.e., $\operatorname{var}\left(\psi \varepsilon_{t}\right)$, that can be attributed to innovations in that market. Let $\psi=\left(\psi_{1}, \psi_{2}, \ldots, \psi_{n}\right)$ be the identical row of $\Psi(1)$. If covariance matrix $\Sigma$ is diagonal, the information share of a price series $\mathrm{j}$ is defined as the proportion of market contribution to the total variance given by, 


$$
I S_{j}=\frac{\psi_{j}^{2} \sigma_{j j}}{\psi \Sigma \psi^{T}}
$$

Equation 6 is a case when price innovations across markets are uncorrelated. If the covariance matrix is not diagonal, then the information share is given by,

$$
I S_{j}=\frac{\left([\psi F]_{j}\right)^{2}}{\psi \Sigma \psi^{T}}
$$

where $\mathrm{F}$ is the Cholesky factorization of $\Sigma$ and it is the lower triangular factorization. $[\psi F]_{j}$ is the $\mathrm{j}$-th element of the row vector $\psi F$.

Baillie et al. (2002) show the average of the lower and upper bounds of the estimates of $\mathrm{IS}_{\mathrm{j}}$ in a bivariate system is a reasonable estimate of a market's contribution to price discovery. In the case of the trivariate system, the mean of the information shares from all orderings implies the estimate of market's contribution to price discovery.

\section{Empirical Results and Research Findings}

At first, the cointegration analysis is employed to detect long-run dynamic relationships among these price series before examining the information transmission pattern. Cointegration theory suggests that two non-stationary series having same stochastic trend, tend to move together over the long run (Engle \& Granger, 1987). However, deviation from long-run equilibrium can occur in the short run. The Johansen full information multivariate cointegrating procedure (Johansen, 1991; Johansen \& Juselius, 1990) is widely used to perform the cointegration analysis. It can only be performed between the series having same degree of integration. The null hypothesis of at most $r$ cointegrating vectors against a general alternative hypothesis of more than $r$ cointegrating vectors is tested by trace statistics.

The result in Table 5 shows that the gold futures prices of COMEX, MCX, and TOCOM are cointegrated with two unique cointegrated relationships as $r \leq 2$ is significant at the $5 \%$ level. In addition, they are all driven by one common stochastic factor. This test for cointegrating vectors ensures that each series can be represented by an error correction model.

Table 5

Johansen Trace Test for Cointegration

\begin{tabular}{llcl}
\hline Log price series & Hypothesis & Trace statistic & 0.05 critical value \\
\hline COMEX, MCX, TOCOM & $r=0$ & 114.94 & 24.28 \\
& $r \leq 1$ & 23.98 & 12.32 \\
& $r \leq 2$ & 2.90 & 4.13 \\
\hline
\end{tabular}

Note. $r$ stands for the number of cointegrating vectors and the number of cointegrating vectors can be at most two because there are three series in each test.

\section{Results on VECM}

To determine the optimal lag lengths, this study follows the method of Xu and Fung (2005) to check the model with the lag number of one, two, and three. From Table 6, it is found that the model with two lags yields the lowest Bayesian Information Criterion (BIC). Consequently, the two-lag model is the most rational model specification. 
Table 6

Lead-Lag Relationships for Three Major Gold Futures Markets

Panel A: Estimated Results of COMEX Equation

\begin{tabular}{|c|c|c|c|c|c|c|c|c|}
\hline \multirow{3}{*}{ Equation (1) } & \multicolumn{6}{|c|}{$\alpha, \beta, \gamma$} & \multicolumn{2}{|l|}{$\theta, \tau$} \\
\hline & \multicolumn{2}{|c|}{ Own-market return } & \multicolumn{2}{|c|}{ Cross-market return (MCX) } & \multicolumn{2}{|c|}{ Cross-market return (TOCOM) } & \multicolumn{2}{|c|}{ Error correction terms } \\
\hline & Lag 1 & Lag 2 & Lag 1 & Lag 2 & Lag 1 & Lag 2 & $\begin{array}{l}\text { Vs } \\
\text { MCX }\end{array}$ & $\begin{array}{l}\text { Vs } \\
\text { TOCOM }\end{array}$ \\
\hline COMEX & $\begin{array}{l}0.0882^{\mathrm{a}} \\
(4.72)\end{array}$ & $\begin{array}{l}-0.0479^{\mathrm{a}} \\
(-4.87)\end{array}$ & $\begin{array}{l}-0.7049^{\mathrm{a}} \\
(-29.56)\end{array}$ & $\begin{array}{l}-0.2353^{\mathrm{a}} \\
(-16.34)\end{array}$ & $\begin{array}{l}0.0132^{\mathrm{c}} \\
(1.84)\end{array}$ & $\begin{array}{l}-0.0095 \\
(-1.35)\end{array}$ & $\begin{array}{l}0.0012^{\mathrm{a}} \\
(2.64)\end{array}$ & $\begin{array}{l}-0.0004^{b} \\
(-2.50)\end{array}$ \\
\hline
\end{tabular}

Panel B: Estimated Results of MCX Equation

\begin{tabular}{|c|c|c|c|c|c|c|c|c|}
\hline \multirow{3}{*}{ Equation (2) } & \multicolumn{6}{|c|}{$\alpha, \beta, \gamma$} & \multirow{2}{*}{\multicolumn{2}{|c|}{$\begin{array}{l}\theta, \tau \\
\text { Error correction terms }\end{array}$}} \\
\hline & \multicolumn{2}{|c|}{ Own-market return } & \multicolumn{2}{|c|}{ Cross-market return (COMEX) } & \multicolumn{2}{|c|}{ Cross-market return (TOCOM) } & & \\
\hline & Lag 1 & Lag 2 & Lag 1 & Lag 2 & Lag 1 & Lag 2 & $\begin{array}{l}\text { Vs } \\
\text { COMEX }\end{array}$ & $\begin{array}{l}\text { Vs } \\
\text { TOCOM }\end{array}$ \\
\hline $\mathrm{MCX}$ & $\begin{array}{l}-0.3265^{\mathrm{a}} \\
(-11.43)\end{array}$ & $\begin{array}{l}-0.1206^{\mathrm{a}} \\
(-7.05)\end{array}$ & $\begin{array}{l}-0.3245^{\mathrm{a}} \\
(-14.52)\end{array}$ & $\begin{array}{l}-0.1855^{\mathrm{a}} \\
(-15.73)\end{array}$ & $\begin{array}{l}-0.0305^{\mathrm{a}} \\
(-3.55)\end{array}$ & $\begin{array}{l}-0.0358^{\mathrm{a}} \\
(-4.26)\end{array}$ & $\begin{array}{l}0.0052^{\mathrm{a}} \\
(3.87)\end{array}$ & $\begin{array}{l}0.0052^{\mathrm{a}} \\
(4.44)\end{array}$ \\
\hline
\end{tabular}

Panel C: Estimated Results of TOCOM Equation

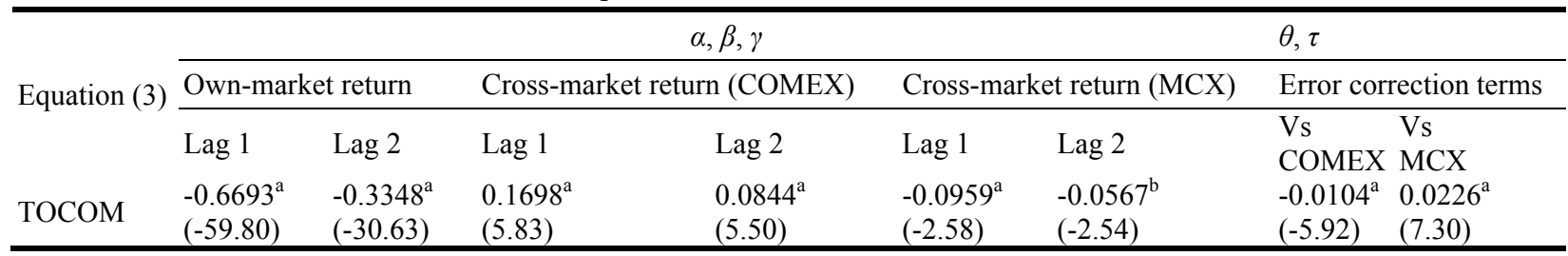

Notes. a, b, and c are significant at the $1 \%, 5 \%$, and $10 \%$ level, respectively and t-statistic values are in parenthesis.

To interpret which market is the leading market, the coefficients of the return of each market $(\alpha, \beta, \gamma)$ in a pair setting (COMEX vs MCX, COMEX vs TOCOM, and MCX vs TOCOM) are compared. A positive and significant error correction term shows that a change in return in this market results in price adjustment in the other and implies that this is the leading market. In the case that both markets have positive sign of coefficient value, leading market is the market that has higher coefficient value.

At first, the coefficients of cross-market return between COMEX and TOCOM which is in Equation 1 and Equation 3 are compared. The cross-market lag returns of TOCOM in Equation 1 is significant only in lag 1 at the value of 0.0132 whereas the cross-market lag returns of COMEX in Equation 3 are significant in both lag 1 and lag 2 at the value of 0.1698 and 0.0844 , respectively. It is implied that a change in return of COMEX pronounces more effects to TOCOM than the other way around $(0.1698>0.0132)$. In other words, COMEX leads TOCOM.

For the pair of COMEX and MCX, the coefficients of cross-market lag return between Equation 1 and Equation 2 are compared. The cross-market lag returns of MCX in Equation 1 are significant in both lag 1 and lag 2 at the value of -0.7049 and -0.2353 whereas the cross-market lag returns of COMEX in Equation 2 are also significant in both lag 1 and lag 2 at the value of -0.3245 and -0.1855 , respectively. Due to negative sign of coefficient value, interpretation in this case does not make any sense.

For the pair of MCX and TOCOM, the coefficients of cross-market lag return between Equation 2 and Equation 3 are compared. Although the cross-market lag returns are significant, they are all in negative value. Thus, it can be concluded that there is a bidirectional but asymmetric information transmission between 
COMEX and MCX and between MCX and TOCOM. Up to this point, the lead-lag relationship for the two latter cases still cannot be determined.

In addition, it is noted that cross-market coefficients of lagged return measure the short-run impact of one market on another. The coefficients of lagged intraday return of own-market and cross-market on Equation 1, Equation 2, and Equation 3 are non-zero and significant in almost all cases excepting the lagged return of TOCOM toward the US return on the Equation 1. These evidences suggest that information flows rapidly among three gold futures exchanges, and that trading information from one market (especially for COMEX and MCX) can be impounded into the others within five-minute trading time. This is not surprising, given that any temporary mispriced gold futures contracts can be heavily arbitraged across markets, this five-minute interval is reasonably more than enough to make riskless profits.

Furthermore, another important measure to investigate the lead-lag relationships is the coefficients of the error correction terms ( $\theta$ and $\tau$ ) that reflecting the price adjustment toward the long-run equilibrium relationship between any two of these three exchanges. To approach equilibrium price, market with higher error correction term value would correct its price in a higher degree of price adjustment or it implies that this market is not a leading market. In contrast, market that yields the lowest coefficients of the error correction terms is a leading market. At first, the results from Table 7 show that the coefficients of $\theta$ and $\tau$ terms in all three equations are significant at the $1 \%$ level. Therefore, it suggests that any market reacts with respect to all markets to maintain equilibrium. Moreover, the significance of the error correction terms supports the results from Johansen cointegration test in Table 6. After comparing the coefficients of the error correction terms, those in Equation 1 are significant with the lowest magnitudes (-0.004 for COMEX and TOCOM and 0.0012 for COMEX and MCX). This implies that COMEX responds to any new arrival information at the lower level of price adjustment. Moreover, the highest magnitudes of these terms ( $\theta$ and $\tau$ ) come from Equation 3. This confirms the evidence that TOCOM gold futures prices tend to adjust at much higher level to correct disparity across market than do MCX or COMEX prices.

\section{Result of Hasbrouck Information Shares}

On the ordering of variables basis, the average information shares of all ordering to measure the price discovery function of each gold futures market are reported in Table 7.

Table 7

The Estimates of the Information Shares

\begin{tabular}{lccc}
\hline & COMEX & MCX & TOCOM \\
\hline Information shares (\%) & 37.09 & 34.66 & 28.25 \\
\hline Note. The estimates are obtained from the means of all ordering of variables in the Cholesky factorization of the residual
\end{tabular}
covariance matrix.

The information shares of COMEX (37.09\%) are more than those of MCX (34.66\%) and TOCOM (28.25\%). Thus, COMEX still captures the most contribution to price discovery. This suggests that US plays relatively more important role than Indian and Japanese market, and is a global leader in the gold futures market.

\section{Conclusions}

This paper investigates information transmission across major gold futures markets located in three 
different regions (COMEX, MCX, and TOCOM). The main concept of this research is no matter where gold futures traded, they share the same underlying asset. The majority of researches in price transmission area examine this relationship via spot and futures markets. Then, there will not be any issue because trading hours of spot and futures exchanges are the same or mostly overlapped. However, in the case of price discovery investigation based solely on futures markets across nations, one should be concerned with non-overlapped trading times. For equity listed in more than one exchanges across nations, researcher could not use price information from the same trading time because of time zone difference. However, after extending trading hour in gold futures market, the trading hours of these three markets are synchronized. To apply synchronous data series, the lead-lag relationship among exchanges can be precisely identified. The five-minute intraday price data from April to August 2011 are applied to two well-documented approaches classifying directions of information flows and news processing abilities among markets. Consistently with many literatures (Xu \& Fung, 2005) which use daily data in their analysis, it is found that the price series on three gold futures exchanges (COMEX, MCX, and TOCOM) are cointegrated suggesting that these price series are driven by the same fundamentals. Based on synchronous data, both VECM and Hasbrouck approach indicate that COMEX play a dominant role in global gold futures trading. Therefore, it can be concluded that the US gold futures market is the most efficient in processing information. Its role on price discovery and information transmission can be attributed to COMEX's massive trading volume.

The Hasbrouck model indicates that the futures in the three countries contribute close to one another $($ COMEX $=37.09, \operatorname{MCX}=34.66$, and TOCOM $=28.25)$. This suggests that although COMEX appears to mostly contribute in price discovery, information transmission across three gold futures markets is extremely rapid. This can be supported by the VECM result. During the five-minute information transmission, only the first lag is significant implying that the trading information of the offshore market is completely impounded in the gold futures price within five minutes.

This study adds to the finance literature in the area of inter-market analysis. It highlights the importance of US gold futures markets and provides alternative insights into the dynamic behavior of information transmission in the global gold system. This evidence is important for any market participants in this era of gold investment.

\section{References}

Baillie, R. T., Booth, G. G., Tse, Y., \& Zabotina, T. (2002). Price discovery and common factor models. Journal of Financial Markets, 5(3), 309-321.

Bhar, R., \& Hamori, S. (2004). Information flow between price change and trading volume in gold futures contracts. International Journal of Business and Economics, 3, 45-56.

Booth, G. G., \& Ciner, C. (1997). International transmission of information in corn futures markets. Journal of Multinational Financial Management, 7, 175-187.

Booth, G. G., Lee, T. H., \& Tse, Y. (1996). International linkages in Nikkei stock index futures markets. Pacific Basin Journal, 4 , 59-76.

Chaihetphon, P., \& Pavabutr, P. (2009). Price discovery in the Indian gold futures market. Journal of Economics and Finance, $34(4), 455-467$.

De Jong, F. (2002). Measures of contributions to price discovery: A comparison. Journal of Financial Markets, 5, 323-327.

De Jong, F., \& Donders, M. W. M. (1998). Intraday lead-leg relationships between futures, options, and stock markets. European Finance Review, 1, 337-359.

Dhillon, U. S., Lasser, D. J., \& Watanabe, T. (1997). Volatility, information, and double versus walrasian auction pricing in US and Japanese futures markets. Journal of Banking and Finance, 21, 1045-1061. 
Engle, R. F., \& Granger, C. W. J. (1987). Co-integration and error correction: Representation, estimation, and testing. Econometrica, 55(2), 251-276.

Eun, C., \& Shim, S. (1989). International transmission of stock market movements. The Journal of Financial and Quantitative Analysis, 24(2), 241-256.

Fleming, J., Ostdiek, B., \& Whaley, R. E. (1996). Trading costs and the relative rates of price discovery in stock, futures, and options markets. Journal of Futures Markets, 16(4), 353-387.

Fung, H. G., Leung, W. K., \& Xu, X. E. (2001). Information role of U.S. futures trading in a global financial market. The Journal of Futures Markets, 21(11), 1071-1090.

Ghosh, A., Saidi, R., \& Johnson, K. H. (1999). Who moves the Asia-Pacific stock markets-US or Japan? Empirical evidence based on the theory of cointegration. The Financial Review, 34, 159-170.

Gonzalo, J., \& Granger, C. W. J. (1995). Estimation of common long-memory components in cointegrated systems. Journal of Business \& Economic Statistics, 13(1), 27-36.

Harris, F. H., McInish, T. H., Shoesmith, G. L., \& Wood, R. A. (1995). Cointegration, error correction, and price discovery on informationally linked security markets. The Journal of Financial and Quantitative Analysis, 30(4), 563-579.

Hasbrouck, J. (1995). One security, many markets: Determining the location of price discovery. Journal of Finance, 50, 1175-1199.

Hua, R., \& Chen, B. (2007). International linkages of the Chinese futures markets. Applied Financial Economics, 17, $1275-1287$.

Hua, R., Lu, B., \& Chen, B. (2010). Price discovery process in the copper markets: Is Shanghai futures market relevant? Review of Futures Markets, 18(3).

Johansen, S. (1988). Statistical analysis of cointegration vectors. Journal of Economic Dynamics and Control, 12(2-3), 231-254.

Johansen, S. (1991). Estimation and hypothesis testing of cointegration vectors in gaussian vector autoregressive models. Econometrica, 59(6), 1551-1580.

Johansen, S., \& Juselius, K. (1990). Maximum likelihood estimation and inference on cointegration-With applications to the demand for money. Oxford Bulletin of Economics and Statistics, 52, 169-210.

Kawaller, I. G., Koch, P. D., \& Koch, T. W. (1987). The temporal relationship between S\&P 500 futures and the S\&P 500 index. Journal of Finance, 42, 1309-1329.

Koa, C., \& Wan, J. (2009). Information transmission and market interactions across the Atlantic-An empirical study on the natural gas market. Energy Economic, 31(1), 152-161.

Kwan, A. C. C., Sim, A. B., \& Cotsomitis, J. A. (1995). The casual relationship between equity indices on world exchanges. Applied Economics, 27, 33-37.

Lehmann, B. (2002). Some desiderata for the measurement of price discovery across markets. Journal of Financial Markets, 5 , 259-276.

Liu, Q., \& An, Y. (2011). Information transmission in informationally linked markets: Evidence from US and Chinese commodity futures markets. Journal of International Money and Finance, 30(5), 778-795.

Martens, M. (1998). Price discovery in high and low volatility periods: Open outcry versus electronic trading. Journal of International Financial Markets, Institutions \& Money, 8, 243-260.

Pizzi, M., Economopoulos, A., \& O’Neill, H. (1998). An examination of the relationship between stock index cash and futures market: A cointegration approach. Journal of Futures Markets, 18, 297-305.

Schreiber, P. S., \& Schwartz, R. A. (1986). Price discovery in securities markets. Journal of Portfolio Management, 12, 43-48.

Stoll, H. R., \& Whaley, R. E. (1990). The dynamics of stock index and stock index futures returns. Journal of Financial and Quantitative Analysis, 25, 441-468.

Wang, G., \& Yau, J. (2000). Trading volume, bid-ask spread, and price volatility in futures markets. Journal of Futures Markets, 20, 943-970.

$\mathrm{Xu}, \mathrm{X} .$, \& Fung, H. (2005). Cross-market linkages between U.S and Japanese precious metals futures trading. International Financial Markets, 15(2), 107-124. 